\title{
A social work study on the effect of controlling self-talk on women's life satisfaction
}

\author{
Faezeh Rostami Najafabadi $^{a^{*}}$, Najmeh Sedrpoushan ${ }^{\mathrm{b}}$, and Farzaneh Niknejadi ${ }^{\mathrm{c}}$
}

${ }^{a}$ MA Student, Counseling Department, Islamic Azad University of Khomeinishahr, Khomeinishahr Branch, Daneshjou Blvd, Iran

${ }^{b}$ Assistant Professor, Counseling Department, Islamic Azad University of Khomeinishahr, Khomeinishahr Branch, Daneshjou Blvd, Iran

${ }^{c}$ Assistant Professor, Counseling Department, Islamic Azad University of Khomeinishahr, Khomeinishahr Branch, Daneshjou Blvd, Iran

\section{H R O N I C L E}

\section{Article history:}

Received May 12, 2013

Received in revised format

25 June 2013

Accepted 12 August 2013

Available online

August 142013

Keywords:

Self-talk

Counseling

Life satisfaction

\begin{abstract}
A B S T R A C T
This paper presents an empirical investigation on measuring the effects of controlling self-talk on women's life satisfaction. The proposed study selected a sample of 34 women who visited counseling center in city of Najaf Abad, Iran. The study divided them into two groups of experiment and control where the first group were requested into eight counseling sessions of 90 minutes on controlling self-talk for a period of two months. The instrument in this study was Enrich couple satisfaction questionnaire, which measured the couple's satisfaction in twelve different categories. The data was analyzed using covariance analysis method and the test results indicated that instructing internal self-talking could increase the rate of couple's satisfaction $(\mathrm{p}<0.05)$.
\end{abstract}

\section{Introduction}

During the past few years, there have been tremendous efforts on learning more about the effects of self-talk on human life (Hardy, 2006). A motivational self-talk seems to have positive influence on improving work skills (Boroujeni \& Shahbazi, 2011). Kolovelonis et al. (2011), for instance, examined the impacts of instructional and motivational self-talk on students' motor task performance in a chest pass and a modified push-ups test in physical education. They reported that that both selftalk groups could surpass control group in both tasks. Instructional and motivational self-talk, in their survey, were equally effective in the chest pass test, but motivational self-talk was more effective compared with instructional self-talk in the modified push-ups test. Reichl et al. (2013) investigated the effect of self-talk frequency on loneliness, need to belong, and health among German adults and confirmed that need to belong and loneliness correlated with health outcomes. 
Boroujeni and Ghaheri (2011) investigated the impact of motivational self-talk (MST) on the auditory whole body, simple and choice reaction time (RT). They also examined the relationship between participants' belief in self-talk and performance. They reported that there were no significant differences between pre-test and post-test of whole body and simple reaction time. In addition, bivariate correlation demonstrated no significant correlation between belief in self-talk and performance. The results recommended that using motivational self-talk could help react relatively fast in choice reaction time tasks. Brinthaupt et al. (2012) investigated differences in self-talk frequency as a function of age, only-child, and imaginary childhood companion status.

Theodorakis et al. (2008) tried to develop an instrument assessing the functions of self-talk (ST) in sports. They conducted two studies for the development of the Functions of Self-Talk Questionnaire (FSTQ). In the first study, a prospective instrument was reported based on empirical evidence and a series of preliminary exploratory factor analysis and the results backed a five-dimensional 25-item solution. In other study, the psychometric properties of the new questionnaire were examined using confirmatory factor analysis (CFA) and confirmed the hypothesized factor structure of the FSTQ. In addition, reliability analyses yielded further evidence regarding the psychometric integrity of the instrument. The results of their study provided preliminary evidence regarding the multidimensionality of ST functions, recommending that ST in sports could serve to enhance attentional focus, increase confidence, regulate effort, control cognitive and emotional reactions, and trigger automatic execution. The FSTQ appeared to be a psychometrically sound instrument, which could help with enhancing our understanding regarding the implementation and effectiveness of ST.

\section{The proposed study}

This paper presents an empirical investigation on measuring the effects of controlling self-talk on women's life satisfaction. The proposed study selected a sample of 34 women who visited counseling center in city of Najaf Abad, Iran. The study divided them into two groups of experiment and control and the first group were requested into eight counseling sessions of 90 minutes on controlling selftalk for a period of two months. The instrument in this study was Enrich couple satisfaction questionnaire (Hawley \& Olson, 1995; Olson \& Olson, 1999), which measured the couple's satisfaction in twelve different categories. The following summarizes all twelve hypotheses of the survey,

Main hypothesis: Learning more about how to control self-talk increases women's marital life satisfaction.

Sub-hypotheses:

1. Learning more about how to control self-talk increases women's conventionality.

2. Learning more about how to control self-talk increases women's marital satisfaction.

3. Learning more about how to control self-talk increases women's personality issues.

4. Learning more about how to control self-talk increases women's marital communication.

5. Learning more about how to control self-talk increases women’s conflict resolution.

6. Learning more about how to control self-talk increases women's financial management.

7. Learning more about how to control self-talk increases women's pleasure activities.

8. Learning more about how to control self-talk increases women's marriage and children. 
As we can observe, there is one main hypothesis and eight sub-hypotheses with the proposed study of this paper. Fig. 1 demonstrates some personal characteristics of the participants.

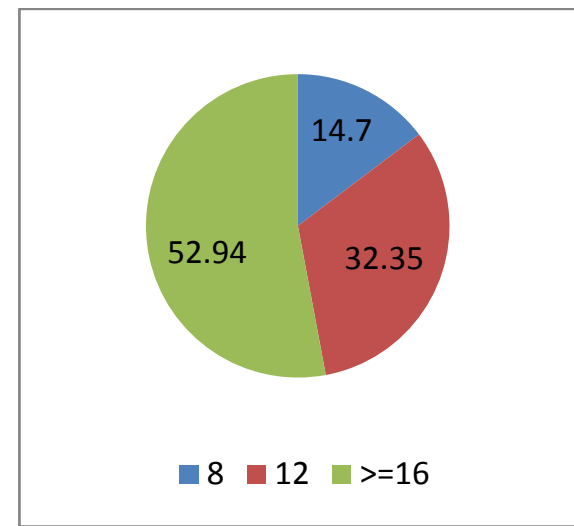

Years of educations

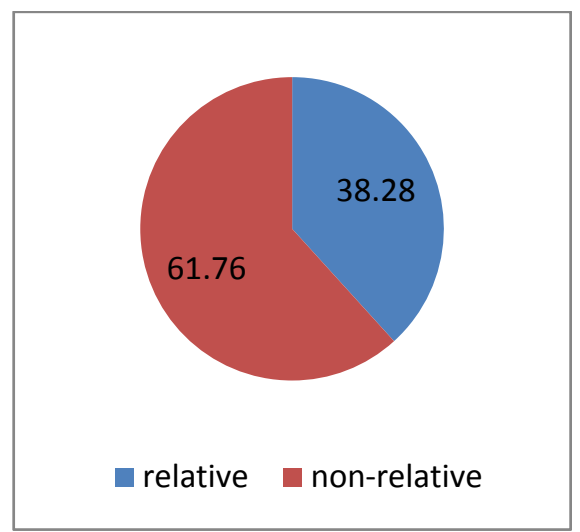

Partner is relative/non-relative

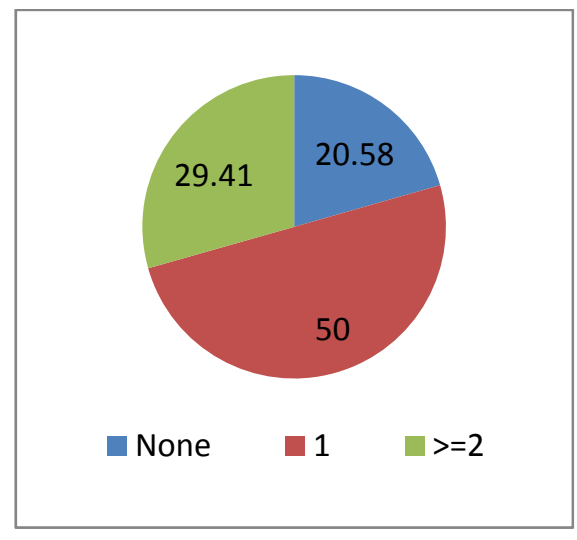

Number of children

Fig. 1. Personal characteristics of the participants

As we can observe from Fig. 1, more than half of the participants maintain, at least, a bachelor degree, over two-third of the participants married to non-relative partners and finally, most participants had, at least, one child. In addition, Table 1 demonstrates the average age as well as the number of years they married in two groups of experiment and control.

Table 1

The results of some basic statistics

\begin{tabular}{|c|c|c|}
\hline 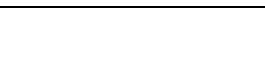 & \multicolumn{2}{|c|}{ Years } \\
\hline Variable & Experiment & Control \\
\hline Age & 32.4 & 31.9 \\
\hline Marriage time & 9.5 & 10.1 \\
\hline
\end{tabular}

The results of Table 1 indicate that most women who participated in our survey were middle age and they had about 10 years of common life with their partners. Before, we examine the hypotheses of this survey, we need to make sure that they are normally distributed. This could be accomplished using Kolmogorov-Smirnov (KS) test and the results are summarized in Table 2 as follows,

Table 2

The summary of performing normality test using Kolmogorov-Smirnov

\begin{tabular}{llcc}
\hline & & Kolmogorov-Smirnov & P-value \\
\hline \multirow{2}{*}{ Pre-test } & Control & 0.916 & 0.37 \\
& Experiment & 0.687 & 0.73 \\
\hline Post-test & Control & 0.95 & 0.31 \\
& Experiment & 0.79 & 0.61 \\
\hline
\end{tabular}

The results of Table 2 clearly indicate that the data for both groups, pre-test and post-test, are normally distributed when the level of significance is five percent. We have also examined the normality test on components of the survey and Table 3 demonstrates the results of our survey. The results of Table 3 clearly specify that all components of the survey follow normal distribution. One of primary assumption on using analysis of variance is to have homogeneity of variance and this could be verified using Levin test. 


\section{Table 3}

The summary of Kolmogorov-Smirnov test of different scales

\begin{tabular}{lcc}
\hline Scale & Kolmogorov-Smirnov & P-value \\
\hline Conventionality & 0.67 & 0.73 \\
Marital satisfaction & 0.98 & 0.28 \\
Personality issues & 0.69 & 0.72 \\
Marital communication & 0.55 & 0.92 \\
Conflict resolution & 0.78 & 0.56 \\
Financial management & 0.73 & 0.65 \\
Pleasure activities & 0.65 & 0.73 \\
Marriage and children & 0.74 & 0.64 \\
\hline
\end{tabular}

The results of test for two groups of experiment and control yields (F-value $=2.49, P$-value $=0.06$ ), which means that the assumption of homogeneity of variance holds ( $\mathrm{P}$-value $>0.05$ ) for the main hypothesis of the survey. In addition, Table 4 summarizes the results of our findings on testing retail scales.

Table 3

The summary of Levin test of different scales

\begin{tabular}{lccc}
\hline Scale & F-value & df & P-value \\
\hline Conventionality & 1.42 & 3,64 & 0.21 \\
Marital satisfaction & 0.19 & 3,64 & 0.90 \\
Personality issues & 1.24 & 3,64 & 0.41 \\
Marital communication & 1.93 & 3,64 & 0.14 \\
Conflict resolution & 2.11 & 3,64 & 0.08 \\
Financial management & 2.09 & 3,64 & 0.11 \\
Pleasure activities & 0.29 & 3,64 & 0.71 \\
Marriage and children & 0.21 & 3,64 & 0.82 \\
\hline
\end{tabular}

Again, the results of Table 3 demonstrate that all homogeneity of variance holds.

\section{The results}

In this section, we present details of our findings on testing the main as well as 8 sub-hypotheses of the survey. The main hypothesis of the survey examine whether learning more about how to control self-talk increases women's marital life satisfaction or not. Table 4 shows details of analysis of variance (ANOVA) on the effect of self-talk on post-test group.

\section{Table 4}

The results of ANOVA test

\begin{tabular}{lccccccc}
\hline & Sum of Square & df & Mean of square & F & P-value & Effect & Statistical power \\
\hline Pre-test & 169986.23 & 1 & 169986.23 & 319.87 & 0.000 & 0.79 & 1 \\
Group & 10123.42 & 1 & 10123.42 & 18.16 & 0.001 & 0.25 & 0.98 \\
\hline
\end{tabular}

The result of ANOVA test shows that there is a meaningful difference between pre-test and group when the level of significance is one percent. Next, we apply ANOVA test on retail scales and the results are summarized on Table 5 as follows, 
Table 5

The results of ANOVA test

\begin{tabular}{lcccccccc}
\hline & $\begin{array}{c}\text { Sum of } \\
\text { Square }\end{array}$ & df & $\begin{array}{c}\text { Mean of } \\
\text { square }\end{array}$ & F & P-value & $\begin{array}{c}\text { Effect } \\
\begin{array}{c}\text { Statistical } \\
\text { power }\end{array}\end{array}$ Hypothesis \\
\hline Conventionality & 6.41 & 1 & 6.41 & 2.19 & $0.16>0.05$ & 0.04 & 0.31 & Not-confirmed \\
Marital satisfaction & 23.1 & 1 & 23.1 & 2.91 & $0.02<0.05$ & 0.05 & 0.76 & Confirmed \\
Personality issues & 53.72 & 1 & 53.72 & 6.11 & $0.02<0.05$ & 0.02 & 0.13 & Confirmed \\
Marital communication & 78.96 & 1 & 78.06 & 8.15 & $0.008<0.05$ & 0.19 & 0.78 & Confirmed \\
Conflict resolution & 155.12 & 1 & 155.12 & 13.41 & $0.001<0.05$ & 0.25 & 0.91 & Confirmed \\
Financial management & 66.09 & 1 & 66.09 & 4.01 & $0.03<0.05$ & 0.10 & 0.81 & Confirmed \\
Pleasure activities & 85.07 & 1 & 85.07 & 12.18 & $0.001<0.05$ & 0.19 & 0.82 & Confirmed \\
Marriage and children & 39.14 & 1 & 39.14 & 4.11 & $0.03<0.05$ & 0.10 & 0.84 & Confirmed \\
\hline
\end{tabular}

The results of Table 5 clearly demonstrate that except the first case, all other components are meaningful when the level of significance is five percent. In other words, training programs influence positively on marital satisfaction, personality issues, martial communication, conflict resolution, financial management, pleasure activities as marriage and children but it did not have any positive impact on conventionality.

\section{Conclusion}

In this paper, we have presented an empirical investigation to find the effects of taking part in training programs on having better control on self-talk issues. The survey has been accomplished among women who participated in a 2-month training program to learn how to cope with their self-talk behavior. The results of the survey have confirmed that taking part in training programs could help patients have better control on their marital satisfaction, personality issues, martial communication, conflict resolution, financial management, pleasure activities as marriage and children but it did not have any positive impact on conventionality.

\section{Acknowledgment}

The authors would like to thank the anonymous referees for construction comments on earlier version of this paper, which have significantly contributed to the quality of the survey.

\section{References}

Brinthaupt, T. M., \& Dove, C. T. (2012). Differences in self-talk frequency as a function of age, onlychild, and imaginary childhood companion status. Journal of Research in Personality, 46(3), 326333.

Boroujeni, S. T., \& Ghaheri, B. (2011). The effect of motivational self-talk on reaction time. Procedia-Social and Behavioral Sciences, 29, 606-610.

Boroujeni, S. T., \& Shahbazi, M. (2011). The effect of instructional and motivational self-talk on performance of basketball's motor skill. Procedia-Social and Behavioral Sciences, 15, 3113-3117.

Hardy, J. (2006). Speaking clearly: A critical review of the self-talk literature. Psychology of Sport and Exercise, 7(1), 81-97.

Hawley, D. R., \& Olson, D. H. (1995). Enriching newlyweds: An evaluation of three enrichment programs. The American Journal of Family Therapy, 23(2), 129-147.

Kolovelonis, A., Goudas, M., \& Dermitzaki, I. (2011). The effects of instructional and motivational self-talk on students' motor task performance in physical education. Psychology of Sport and Exercise, 12(2), 153-158.

Olson, D. H., \& Olson, A. K. (1999). PREPARE/ENRICH program: version 2000. Preventive approaches in couples therapy, 196-216. 
Reichl, C., Schneider, J. F., \& Spinath, F. M. (2012). Relation of self-talk frequency to loneliness, need to belong, and health in German adults. Personality and Individual Differences, 54(2), 241245.

Theodorakis, Y., Hatzigeorgiadis, A., \& Chroni, S. (2008). Self-talk: It works, but how? Development and preliminary validation of the functions of self-talk questionnaire. Measurement in Physical Education and Exercise Science, 12(1), 10-30. 